\title{
PUBLIKATSIOONE
}

\section{FRIEDEBERT TUGLASE SÕNAVÕTT LÄTI KIRJANIKE PÄEVAL RIIA LÄTI SELTSI SAALIS 31. MAIL 1940}

1938. aasta 16. detsembril avati Riia Läti Seltsi ruumes Läti Kirjanduse- ja Kunstikoda. See oli üks organisatsioon nn Läti kodade süsteemist, mis loodi Kārlis Ulmanise valitsemise (1936-1940) ajal ning mille eesmärk oli läti kultuuri edendamine.

Läti kirjandus- ja kunstipäevadele saabus külalisi Eestist ja Leedust. Aasta enne Friedebert Tuglast olid külalisteks Bernard Kangro ja Eduard Hubel ehk Mait Metsanurk, kelle romaan „Ümera jõel” ilmus 1939. aastal läti keeles Jānis Žigursi tõlkes. ${ }^{1}$ Tuglase 1940. aasta reisi laast „Läti muljeid” on ilmunud tema kogutud teoste 11. köites (2014).

Vähem kui kuu aega enne Balti riikide okupeerimist peetud pidulik kõne on tollast poliitilist situatsiooni arvestades ilmselt tahtlikult apoliitiline.

Tuglase raamatukokku kuulub sarjas „Elav teadus” ilmunud letofiil Mart Pukitsa „Läti kultuurilugu” (1937), mis esitab mitu paralleeli meie ja Läti ajaloost. Kõnelejagi mainib lõunanaabrite rahvusliku ärkamisaja ideelist juhti Krišjānis Valdemārsi (1825-1891), Johann Köleri kirjasõpra, kelle väljaanne Pēterburgas Avīzes (Peterburi Ajaleht) oli Carl Robert Jakobsoni Sakala eeskuju. Valdemārs rajas hiljem Heinaste merekooli. „Läti Hurt”, loodusteadlane Krišjānis Barons (1835-1923), oli õppinud Tartu ülikoolis.

Lisaks ajaloolistele paralleelidele toob Tuglas oma kõnes esile eestlasi ja lätlasi siduvad looduslikud ning eriti kultuurilised sarnasused, nimetades muu hulgas ka kummagi rahvalaulude ühisjooni, mida on oma raamatus käsitlenud ka Pukits. Tuglase kõnes mainitud väljapaistva luuletaja Edvarts Virza (1883-1940) kirjanikust, tõlkijast ja diplomaadist lapselaps Anna Žīgure (snd 1948) on aga arvanud dainad eesti regilaulust poeetilisemaks. ${ }^{2}$ Ehk saaks nõnda eristada ka Virza nn Straumeni idülle ehk talupojaelu kujutavat proosapoeemi „Taevaredel. Aasta vanas Semgale talus” („Straumēni”, 1933; eesti k 1937) ning Tammsaare „Tõe ja õiguse” põhitooni. 1939. aastal, mõni aeg pärast „Taevaredeli” eesti keeles ilmumist tekkis Loomingu veergudel läti vasakpoolse kriitiku Lucija Upitte artiklist alanud poleemika, osalisteks veel tõlkija Mart Pukits ja Heiti Talvik. ${ }^{3}$ Upīte süüdistas Virzat autoritaarse režiimi õigustamises ja populariseerimises: Ulmanise Lätis ei saanuks ta

\footnotetext{
${ }^{1}$ Vt Läti hinnang „Ümera jõele”. Kiitev arvustus Mait Metsanurga äsja lätikeelses tõlkes ilmunud romaanile. - Uus Eesti 24. IX 1939, lk 6.

${ }^{2}$ M. Mü üri pe a l, „Taevaredel” sündis Billite talus. - Maakodu 2006, nr 4, lk 8.

${ }^{3}$ L. Upīte, Läti kirjandus aja veskis. - Looming 1939, nr 5, lk 536-540; M. Pukits, Poleemika. Selgituseks. - Looming 1939, nr 7, lk 786-788; H. T a lvi k, Ed. Virza: Taevaredel. - Looming 1939, nr 8, lk 891-893.
} 
ilmselt niisugust kriitikat avaldada. Meie kriitikud nägid Virza „mälestuste nõiapeeglis" - nagu kirjutab Talvik ${ }^{4}$ - märksa rohkemat kui vaid päevapoliitilist tööriista. Virza oli pärast sõda Lätis keelatud autor: kui Tuglas oma kõnet pidas, oli Ulmanis ise seda kuulamas, mõni aeg hiljem poleks Ulmanise preemia laureaati Virzat enam mainidagi saanud.

Lätis tegutses sel ajal mitu vilunud eesti-läti suuna tõlkijat, nagu Tartus õppinud Elīna Zālīte (1898-1955) ja Eestis sündinud Jānis Žìgurs (1915-1988), aga ka eestlannaga abiellunud tulihingeline Eesti-huviline Alfrēds Ķempe (1890-1967), kelle tõlkes ilmus 1941 Eduard Vilde „Mahtra sõda” („Machtras karš”, pidi algselt ilmuma 1940). Kempe lootis kunagi kogu eesti kirjanduse läti keelde tõlkida. ${ }^{5}$ Ta on Lätis avaldanud käsitlusi eesti kirjanikest, luulest ja rahvatantsust. Vastupidisel tõlkesuunal on sel ajal väga oluline Mart Pukitsa, aga ka Karl Abeni nimi. Kõnes mainituist tundis eesti lugeja Kārlis Skalbe (1879-1945) muinasjutte Pukitsa vahendatuna ja Jānis Poruksi (1871-1911) jutustusi nii Pukitsa kui ka Abeni tõlgituna. Rainise (Jānis Pliekšāns, 18651929) näidendid olid ilmunud Abeni, Andrievs Niedra (1871-1942) looming taas Pukitsa tõlkes. Suure realisti Rudolfs Blaumanise (1863-1908) jutustusi ja näidendeid oli jõudnud eesti keelde juba enne nende kahe tõlkija tegevust.

Iseloomustamaks lätlaste huvi eesti kirjanduse vastu väärib tsiteerimist intervjuu Jānis Žigursiga, kes Riigi Ringhäälingu külalisena viibis 1940. aasta kevadel Tallinnas. Läti ringhäälingu kooliraadio toimetajat on küsitletud päevalehes Uus Eesti, milles Žigurs ütleb: „Näiteks Metsanurga „Kutsutud ja seatud" on arvustustes tunnustatud parimaks psühholoogiliseks romaaniks ja sellisena teda kõrvutatud prantslaste omadega. Tehakse sellest nagu intelligentsi mõõdupuu - et kas oled Metsanurga teost lugenud või mitte. Arvan, et oleks väga raske leida kirjandusehuvilist lätlast, kes ei tunneks A. H. Tammsaaret, M. Metsanurka, A. Gailitit, M. Underit, A. Mälku, P. Vallakut ja teisi." ${ }^{6}$ Žigurs mainib ka Riia Kunstiteatri suurt huvi eesti näidendite vastu. Tema saadete kavas oli üle nädala vähemalt üks eesti novell lätikeelses tõlkes, lisaks eesti luulet ja loenguid eesti kultuurist. Tuglase kõnes esile toodud „Põrgupõhja uue Vanapagana" katkenditki oli Žigursi tõlkes juba raadios esitatud ning A. H. Tammsaare mälestamisaktustel 1940. aasta kevadel Lätis ette kantud.

Friedebert Tuglase sõnavõtt läti kirjanike päeval kuulub Tuglase ettevalmistatud kogutud teoste käsikirja „Valitud kõned”, mis on hoiul Underi ja Tuglase Kirjanduskeskuse muuseumiosakonnas.

ELLE-MARI TALIVEE, ANNELI MIHKELEV

${ }^{4}$ H. Talvik, Ed. Virza: Taevaredel, lk 891.

${ }^{5}$ D. Kar e va, Vaimulootsik triiki täis. - Sirp 20. XI 1998.

${ }^{6}$ Uusi eesti teoseid läti keelde. Jutuajamine „Ümera jõel” tõlkija J. Žigursiga. - Uus Eesti 16. IV 1940, lk 7. 
Kõrgeauline härra minister, auline Läti Kirjanduse-ja Kunstikoja juhatus, kallid läti kolleegid!

Ma ei julge kaua teie tähelepanu koormata võõrkeelse kõnega. Lubage mul ainult edasi anda eesti kirjanikkonna siiras tervitus teie organisatsiooni suurteks tööpäevadeks. Teiseks tahan kasutada võimalust oma rõõmuavalduseks, et võin isiklikult osa võtta neist päevadest. Teie mõtted on muidugi sihitud oma maa vaimuelu organiseerimisele ja tõstmisele. Kuid mis saavutate teie, see annab initsiatiivija hoogu ka meile. Olgu teie töö viljakas! Eesti vaimuinimeste mõtted ja südamed on teiega.

[Selle minu eestikeelse sissejuhatuse tôlkis läti keelde Elīna Zālīte. Järgneva kõne kandis ta ette ainult läti keeli:]

\section{Eesti tänapäeva kirjandus.}

Kui ma siin täna eesti kirjanduse esindajana sõna võtan, siis teen ma seda teadmises, et see toimub kuulajaskonna ees, kes pole meile eestlastele kauge ega võõras. Meie rahvaid ühendavad samad looduslikud elutingimused ja seovad samad ajaloolised pärimused. Meie teed nii õnnes kui ka õnnetuses on kulgenud kõrvuti. Kuid põline ühe ja sama mere ääres, ühe ja sama päikese all elamine ei või mõjuta olla meie rahvusmentaliteedi kujunemisele ning sellest võrsunud vaimuvaradele.

Meile pole küll veel täitsa selge, kui palju on meil ühiseid muinaspärandeid. Kuid igatahes on juba juhitud tähelepanu ühisjoontele läti ja eesti rahvalaulu sisu ja aine käsitluses, värsimõõdus ning mõtteparallelismis. Niisama langevad meie muinasjuttude luulekujud suurelt osalt ühte. Veel selgemaks saavad aga paralleelnähtused, nii pea kui jõuame aegadeni, mil kumbki rahvas võis alata juba teadlikult ja organiseeritult oma rahvusliku kultuuri harrastamist. Võtkem kas või kohe ärkamisaja suured kümnendid. Eks seisnud seal kõrvuti kaks suurmeest - teil Krišjānis Valdemārs, meil Carl Robert Jakobson - mitte ainult juhuslikud kaasaegsed, vaid sama vaimu tööriistad. Ja kas ei esinenud seal kõrvuti Krišjānis Barons ja Jakob Hurt-üks töötades küll Moskvas, teine Peterburis, kuid mõtted mõlemal juhitud oma kodumaa muinasluule kogumisele. Ja nii on möödunud hilisemadki aastakümned ühiselt: masendavad venestusajad, sajandi alguse uus ärkamine, rasked Maailmasõja päevad ja lõpuks kummagi maa vabanemine ühises võitluses ühtede ning samade vaenlaste vastu. Jah, ka meie tänapäeva elutingimusis, oludes ja ohtudes on nii palju ühist. Kuid on loomulik, et selline ühine saatus ka ühiseid lootusija kartusi on äratanud, mis on kajastunud meie loominguski. Kui on olnud realiteet sama, ei puudu siis sellest realiteedist tõusnud luulelgi samad tunnusjooned.

Oleme siiski peaaegu nagu sama maa lapsed. Meie eestlased elame vaid pisut põhja pool ja pisut karmimais tingimusis. Sellepärast on meie iseloomgi vahest pisut kinnisem ja tundeelu vähem lüüriline kui teie oma. Kuid kui eestlane loeb Virza Straumeni idülle, siis meenuvad talle kõige kaunimad mälestused ta oma kodutalust. Ja kui lätlane jälgib Tammsaare Vargamäe eepost, küllap siis kangastuvad tallegi ta karmimad kogemused võitlusest oma maaga ning maa eest. 
Olen tahtnud siin rõhutada, et meil on nii palju ühist. Kuid pean ka kohe rõhutama, et me seda ühist küllalt hästi ei tunne. Sest kui teised kunstiväärtused vabalt rahvuspiire ületavad, siis takerdub kirjanduslik looming paratamatult keeletõkke taha. On nii harvad need üksikud kummalgi maal, kes suudavad ühesuguse vabadusega nautida mõlema rahva kirjanduslikku eneseväljendust.

Kuid nende harvade tõttu saame ometi pilgugi heita oma naabri vaimsesse varaaita. Tõlge jääb küll ikka tõlkeks ja temas hukkub paljugi, mis sõltub just keelelisest vormist. Kuid ta võimaldab ometi saada käsituse teise kirjanduse aineist ja probleemest ning luua kujutluse kirjeldatud maa rahvaelust ja mõtteviisist. Eriti hõlbustab seda tõlgitud ilukirjandus just laiemas lugejaskonnas, kellel pole mahti ega eeldusi süveneda teise rahva elu käsitlevaisse ajaloolistesse, etnograafilistesse või sotsiaal-poliitilistesse uurimustesse. Ja ses mõttes on läti kirjandus eestikeelses tõlkes juba senigi palju tänuväärset tutvustamistööd teinud. Sellised nimed nagu Blaumanis, Niedra, Rainis, Poruks, Skalbe, Virza pole eestigi lugejale paljas kõla, nagu pole talle tundmatu ka see läti eluavalduste ring, mida nad on kirjeldanud. Ning teiselt poolt tahan uskuda, et eestigi autorite tõlked on Lätis samasugust tutvustaja osa täitnud.

Kuid sel vastastikusel rikastamisvahendil on ometi olulised puudused. Ta ei saa olla küllalt ulatuslik, tal on hädaoht jääda juhuslikuks ja-kõigepealtta ei saa iial sammu pidada otse tänapäeva loominguga. Tõlkija jõuab oma valikuni aastate ja aastakümnete pärast, välja arvatud ainult üksikud juhused, kus on küsimuses üksikud ainelt sensatsioonilised või juba erakordselt esile ulatuvad teosed. Mis on aga vaheajal sündinud naabermaal? Mis tehakse seal tänapäeval? Millist osa etendab kirjandus otse sel hetkel rahva mõtte ja tundeelu peegeldamisel ning ideelisel selgitamisel?

Kui minu tänaseks ülesandeks on kõnelda mõni sõna eesti kirjandusest, siis ei taha ma igatahes jutustada kirjanduse ajalugu. Ma ei taha teid tüüdata kaugete nimede, pealkirjade ja aastaarvude loetlemisega. Ma püüan vastata võimalikult lihtsalt küsimusele: mis toimub tänapäeva eesti kirjanduses?

On vana tähelepanek: romantiliste kirjandusjärkude domineerivaks vormiks on värss ja lü̈̈rikasse kalduv lühiproosa, realistlikel ajastuil aga peamiselt eepilise ulatusega romaan. Nii on see kordunud ka eesti kirjandusloos. Selle sajandi alguse uusromantiline suund viljeles tulemuslikult lüürikat ja novelli, kuid oli romaani alal väheviljakas. Vastupidi, pärast Eesti iseseisvaks saamist algav realismi taaselustumine tähendas ka romaani osatähtsuse tõusu. Viimane kümnend on olnud otse ta võidukäiguks. Ta on esialale tõusnud mitte ainult oma arvukusega, vaid ta valitseb ka lugejaskonna tähelepanu. Kõik muud kirjanduslikud vormid on ta varju jäänud-olgu see novell, näidend või värss. Jätkub ainult tähendusest, et möödunudki aastal ilmus Eestis umbes 30 algupärast romaani, neist mõnedki nelja-viiesaja-leheküljelised. See pole väike arv meie kirjanduslikes oludes.

See romaani võidukäik ei tulnud ometi mitte järsku. Suurte romaanide traditsioon polnud meil üldse kuigi tugev. Vanarealismi ajastust polegi palju muud mainida kui Eduard Vilde ajalooline triloogia ja mõned sama autori teised teosed. Näis, nagu puuduksid Eestis vastavad talendid, püsivus ja ka 
lihtsalt rahvamajanduslikud eeldused suuremate kompositsioonide loomiseks ning väljaandmiseks. Nii olid Eesti iseseisvusajagi esimesed romaanid sünnilt juhuslikud ja väliselt vähema ulatusega. Alles a. 1926 tegi Anton Hansen Tammsaare algatuse, mis sai teistelegi eeskujuks ja kannustajaks. Sel aastal ilmus nimelt tema viieandelise suurromaani „Tõe ja õiguse” esimene köide. Tammsaare polnud enam noor mees ega algaja. Ta sulest oli ilmunud veerand sajandi jooksul rida pikemaid realistlikke külajutte ja impressionistlikke linnanovelle. Jõudes juba oma viiekümnenda eluaasta künnisele tahtis ta suuremas kompositsioonis anda sünteetilise kokkuvõtte oma nooreea mälestusist, kasvukoha inimümbrusest ja kogunenud elutarkusest. Muidugi ei tarvitse ma läti kuulajaile selgitada Tammsaare suurromaani sisu, - ta on võinud sellega isegi tutvuda, kuigi lühendatud tõlkes. ${ }^{1}$ Vaevalt ulatus aga autorigi kavatsus esialgu esimesest köitest kaugemale. Kuid ta oli eneselegi ootamatult hästi õnnestunud ja ka vastuvõtt oli selle kohane. See oli nagu laiapiirdelise eepilise jutustamisoskuse avastamine eesti kirjanduses. Kaks ja pool tuhat lehekülge argielu kirjeldust - kas see ei võinud igavaks minna? Otse selle vastu - teose psühholoogiline tihedus, intiimne veenvus, ridade vaheltki hõõguv eluhõng tegi ta kõigile lähedaseks.

Pärast selle suure kompositsiooni lõpetamist avaldas Tammsaare veel kaks suuremat romaani - „Elu ja armastus” ning „Ma armastasin sakslast”. Kuid ma tahaksin peatuda ometi ainult ta viimase teose juures, millega ta veel enne oma ootamatut surma hakkama sai. See on imeväärse pealkirjaga ja veel imeväärsema sisuga romaan: „Põrgupõhja uus Vanapagan”, mis ilmus alles möödunud jõuludeks. Ka läti rahvas tunneb lugusid suure jõuga, kuid juhmivõitu vanapaganast ja tema kavalast sulasest, kes oma peremehe igal juhul lõpuks üle lööb. Kuid Tammsaare on kuidagi osanud need grotesksete rahvajuttude tü̈̈bid paigutada meie reaalsesse tänapäeva ja siduda nad kõige aktuaalsemate päevaprobleemidega. Osalt küll päris ehtne vanapagan - isegi väikesed sarvenupud ei puudu, kuid sealsamas ka päris harilik tööori, keda ta „aitajad” tõeliselt alalõpmata tüssavad ja ekspluateerivad. Ja koos autoriga kaldub lugejagi sümpaatia lõpuks selle vanapagana poole. See on kibe, sarkastiline, paradoksaalselt vaimukas teos, mille lõplikku mõtet polegi vahest lihtne avastada. Nagu Tammsaare ise oli väga erandlik kuju eesti kirjanduses, nii jääb selliseks ka ta hüvastijätu teos.

Tammsaare kõrval tuleb kohe mainida teist viljakat romanisti. See on Mait Metsanurk - temagi juba üle kuuekümnenda eluaasta künnise astunud. See on oma ideelisis otsinguis palju rahutum, mitmekülgsem, võiks öelda ka praktilisem autor. Ta on oma suures toodangus püüdnud ikka elavalt reageerida ajastu päevaküsimusile, kord rohkem, kord vähem õnnestudes. Praegu tahaksin ometi tähelepanu juhtida eriti ühele ta algatusele uuemas eesti kirjanduses. Aastal 1934 ilmus Metsanurga romaan eestlaste muistsest vabadussõjast „Ümera jõel”, mis on ka lätikeelses tõlkes tuttav. ${ }^{2}$ Selliseid ajaloolis-isamaalisi romaane oli harrastatud juba ärkamisajale järgnenud ajastul, kuigi hoopis vähenõudlikumal kujul, ja siis oli see laad unarusse jäänud. Nüüd aga lähenes Metsanurk sellele ainete liigile juba nüüdisaegsete ajalooliste teadmiste ja psühholoogiliste nõuetega. Teiselt poolt aga lisas nii autori innukust kui ka lugejaskonna vastuvõtumeeleolu rohkem maksmapääsev rahvuslik suund. Tulemuseks oli sedalaadi ajaloolise ilukirjanduse äkiline võrsumine mõne aasta jooksul. Metsanurgal eneselgi ilmus alles möödunud 
jõuluks suur romaan „Tuli tuha all”, mis kujutab suuri näljaaegu Eestis XVII sajandi lõpul ja maarahva visa võitlust oma õiguste eest. Teistest Metsanurga hilisema aja romaanest olgu mainitud paari aasta eest ilmunud ja Lätiski tuntud „Kutsutud ja seatud”, mis käsitleb juba meie oleviku kirikuelu. ${ }^{3}$

Metsanurga poolt algatatud ajaloolist romaani on viljelnud ka Karl August Hindrey oma kaheköitelises Muinas-Eesti olusid kirjeldavas romaanis „Urmas ja Merike” ning paaris teiseski teoses. See autor on praegu aktiivseist eesti kirjanikest õieti kõige vanem, kuigi ta oma puht-ilukirjanduslikku tegevust algas võrdlemisi hilja. Ajalooliste ainete kõrval on ta eriti viljelnud psühholoogiliselt väga peenekoelist nü̈̈disaja inimese kujutamist nii romaanes kui ka rohkearvulisis novelles. Esimestest olgu eriti mainitud ta „Sündmusteta suvi".

Kõik järgnevad romanistid kuuluvad juba kas kesk-, nooremasse või koguni noorimasse kirjanikepõlve. Siin tuleks jälle mainida suure ajaloolise romaani „Läänemere isandate” autorit August Mälku. See teos kirjeldab väga patriootilises vaimus eesti viikingiaega ja esivanemate kangelastegusid. Samuti ilmus samalt autorilt pisut varem suur ajalooline romaan „Surnud majad”, mille aine on võetud Põhjasõja aegseist Eesti oludest. Ometi on Mälgu erialaks just ta kodukoha - Eesti saarte karmi ja omapärase miljöö kirjeldamine, mida ta on teinud mitmes romaanis ja novellikogus.

Eriti viljakas ja jõuline romanist on Eesti Kirjanikkude Liidu praegune esimees August Jakobson. Ta debüteeris küll alles 1927. aastal üle seitsmesajaleheküljelise romaaniga „Vaeste-patuste alev”, mis käsitles Eesti provintsi proletaarset miljööd ja äratas kohe suurt tähelepanu. Ning sellest peale on ta avaldanud üle kahekümne tüseda köite, peamiselt romaane. See haruldane viljakus on äratanud küll kaksipidi mõtlemist, kuid keegi ei saa ka eitada Jakobsoni järjekindlat, veenvat realismi oleviku Eesti inimtüüpide eritlemises, samuti kui tema probleemide aktuaalsust.

Hoopis piiratum on Johannes Semperi romaanitoodang. Õieti ongi kõne ainult kahest ulatuslikumast teosest, millest viimane, neljasaja-leheküljeline romaan „Kivi kivi pääle” ilmus alles möödunud jõuludeks. Semperi erialaks on eesti haritlastü̈̈pide psühholoogiline eritlemine ja nende elamuste nõelterav kinnistamine. Selleks on autori intellektuaalne hingelaad, kirjanduslik kultuur ja stiilioskus enam kui kohane.

Kõige vähem võiks läti kuulajale tundmatu olla August Gailiti, välismailgi populaarse „Toomas Nipernaadi” autori nimi. Selle kôrval tuleks aga mainida ka ta „Isade maad” ja teisi romaane, samuti kui novellegi. Gailiti fabuleerimise ja grotesksete tü̈̈pide loomise oskus ning ta romantiliselt paisutatud stiil on erandlik eesti romaani üldiselt eepilisemalt vestleval taustal.

Ma tean küll, et paljas autorite loetlemine võorrale kuulajale õieti midagi ei ütle, kuid ma oleksin ülekohtune, kui lõpuks vähemalt üksikuid nimesidki ei mainiks, kellel igaühel ometi on oma kindel koht eesti uuemas kirjanduses. Nii on Richard Roht oma paariskümnes romaanis kirjeldanud peamiselt eesti küla ja alevi olusid, samuti kui ka Mart Raud. Albert Kivikas, hea rahvaelu kirjeldaja, äratas viimati tähelepanu oma suure vabadussõja romaaniga „Nimed marmortahvlil”. Jaan Kärner käsitleb peamiselt oleviku või lähema mineviku ühiskondlikke olusid. Enn Kippel on viljakalt harrastanud ajaloolist romaani ja Adolf Hint ${ }^{4}$ Saaremaa ning meremotiive. Ei tohi mainimata jätta ka vanameister Oskar Lutsu poolmemuaarilist toodangut, Leida Kibuvitsa 
impressionistlikke tüübiromaane või ka Jüri Parijõe peamiselt juba noorsoole määratud jutustusi.

Nii käsitleb eesti tänapäeva romaan kõiki ühiskonna kihte ja ajaloolisi järkusid, muistsest iseseisvusajast kuni käesoleva hetkeni. Ei või muidugi väita, et siin oleks tegemist ainult meisterteostega või et siin ei leiduks koguni päris asjatut ballasti. Kuid me teame ka, et isegi teisejärgu toodangul on vahel oma positiivne osa täita. Ta aitab tihendada üldist kirjanduslikku pinda, millest võrsuvad üksikud ulatuslikumad saavutised. Kirjandus tervikuna on ikkagi kollektiivse töö tulemus. Samuti teame ka, et see eesti romaani õitselelöök poleks mõeldav olnud enne riikliku iseseisvuse saavutamist. Alles nü̈̈d tekkisid tõelised eeldused selle kirjandusliigi harrastamiseks. Sest andekuski ei aita, kui ühiskond pole veel võimeline selle vilja soodustama ja kandma. Seda suudab ta alles meie päevil.

Kui siirdume romaani juurest teiste eesti kirjandusliikide juurde, siis pole siin tõus endisega võrreldes nii märgatav. Viimane kümnend ei tähenda ei kvantitatiivselt ega kvalitatiivselt sellist murrangut. Isegi tehnilis-stiililiselt pole siin suuremaid avastusi tehtud, välja arvatud vahest ainult luulekirjandus. Avardumist ja ajakohastumist tundub muidugi küll nü̈̈disaegsete teemade valikus ja oleviku mentaliteedi maksvusele pääsemises.

Novelli ja lühema jutustuse alal mainigem siin juba varem esinenud nimesid, nagu Hindrey, Metsanurk, Mälk, Jakobson, Kibuvits. Kuid nendegi novellistika liitub vaid osana nende hoopis olulisema romaanitoodangu külge. Erandeiks ses suhtes oleksid vahest ainult Hindrey ja Peet Vallak.

Mis puutub aga näitekirjandusse, siis leidub meil üldse vaid üks puhtakujuline näitekirjaniku tü̈̈p - Lätiski mõne oma teosega tuntud Hugo Raudsepp. ${ }^{5}$ Ta on avaldanud paar piibliainelist draamat, kuid saavutanud oma tõelise menu ikkagi kümmekonna komöödiaga. Ta on erakordselt löögivalmis ja paradoksiviljakas, reageerides väledalt meil päevakorral olevaisse nähtusisse, mille koomika polegi iga kord võõrale arusaadav. Muist viimase aja näidendeist tuleb eriti mainida August Jakobsoni möödunud aastal ilmunud draamat „Viirastused”. See saavutas oma sügavpsühholoogilise ja pineva arengujoonega väga hea menu teatrilaval. Nii linna- kui maalavad nõuavad aga pidevalt algupäraseid näidendeid. Ja selle nõude rahuldamiseks on viimaseil aastail tekkinud otse kümnete ja kümnete kaupa teatritükke. Kuid kahjuks ei või seda peamiselt jantlikku repertuaari kirjanduslikult kuigi kõrgelt hinnata. Teiseks abinõuks algupärase mängumaterjali soetamisel on romaanide ja jutustuste dramatiseerimine. Nii on rohkesti $k a$ eelpool mainitud teostest näitelavale jõudnud ja sel teel laia üldsuse hulgas veelgi populaarsemaks saanud. Ja meie dramatiseerijail on tõesti leidlikkust, oskust ning julgust. Peab uskuma vist sedagi nende hulgas, kes väitis: kui tarvis, dramatiseerin ka Eesti vabariigi raudteede sõiduplaani! Kuid näidendite-kriis pole ainult meie, vaid palju laiema ulatusega häda.

Eesti luulekirjandus pole küll nõnda romaani varju jäänud kui näiteks novell, kuid seda tähtsust tal igatahes pole, mis paarikümne aasta eest. Siis ta otse domineeris kõigi teiste kirjandusliikide üle. Talle on praegugi jäänud oma kindel, kuigi vähenenud hindajatering. Senised luuletajad on enamasti edasi tegutsenudja neile on aeg-ajalt ikka uusi andekaid algajaid lisaks tulnud. Eesti 
moodsa lü̈̈rika rajaja prof. Gustav Suits on küll juba palju aastaid peamiselt kirjandusloo uurimisega tegelenud, aga Marie Underi suur lüüriline and on aina süvenenud ja ta väljendusvorm üha peenenenud. Samuti on Henrik Visnapuu viimasel aastakümnel eriti isamaalaulikuna tuult tiibade alla saanud. Selle aja jooksul on kindla ilme võtnud ka Juhan Sütiste elulähedane ja sõnastusvärske looming, mis täidab juba kümmekond kogu. Teistest nii vanemaist kui nooremaist luuletajaist, kelle tegevus pidevalt jätkub, olgu veel mainitud alatine opositsioonimees Johannes Barbarus, idüllikalduv Hendrik Adamson, tööpaatose ülistaja Erni Hiir, intellektuaalne Valmar Adams, epigrammilise kontuuriselgusega Betti Alver ning lüürilise voolavusega Kersti Merilaas. Möödunudki aastal ilmus Eestis paarkümmend uut luuletuskogu.

Ometi ei piirdu ühegi rahva kirjanduslik elu ainult ilukirjanduslikkude teoste enestega, vaid sellesse liitub veel muidki komponente. Siin tuleb arvestada ka kirjanduse ja rahva vastastikust suhet ning mõju, ideelisi väitlusi kirjanduse ümber, arvustust, esseistikat ja osalt kirjandusloo uurimistki. Mis puutub huvisse kirjanduse vastu Eestis, siis on see vähemalt romaanide puhul ilmne. Seda tõendavad kõiksugused ankeedid, kirjanduslikud kohtud ja muud reageeringud. Seevastu on küll kirjanduses eneses suunavõitlused peaaegu vaikinud ega või enam kujutledagi selliseid poleemikaid kui alles kümne aasta eest. Ometi näib meie kirjanduslik areng juba mingile uuele murrangule lähenevat, sest praeguse hetke tundeelu ei taha nagu enam hästi sobida seni valitsenud realismi raamidesse.

Tahan lõpetada oma põgusa ülevaate usus, et eesti kirjanduslik elu on midagi tõesti elavat ja arenevat. Kirjandus pole nüüdsel ajal miski isoleeritud, ainult üksikuile määratud ajaviide, vaid ta on tihedas sidemes kogu rahva organismi kasvu ja võimastumisega. Sellisena tahame ja võime loodetavasti näha ka eesti kirjandust.

Mulle on õnn osaks saanud läti kirjanduslikke suurpäevi kaasa elada. Osalt tean, osalt aiman, et läti kolleege samad küsimused huvitavad ja liikvele panevad, mis meiegi kirjanikke. Kummagi liitlasrahva kultuurielu huvides oleks, kui meie kirjandustegelased ikka lähema kontakti saavutaksid. Sest see kannustaks, annaks hoogu ja indu meie edasi ründamisel. Kuid iga vaimne võit ühel pool piiri tähendab seda kaudselt ka teisel pool.

Ma tean, lätlased tarvitavad ütlemata ilusat kõnekäändu, soovides mingile meeldivale nähtusele kauast kestvust. Nad soovivad sellele päikese iga. Lubage ka minul läti kultuuri loovale vaimule ja selle kandjaile päikese iga soovida.

1. „Zeme un mīlestība”, 1-4, Elīna Zālīte tõlkes ilmus 1936.

2. „Imeras kauja” Janis Žigursi tõlkes ilmus 1939.

3. „Aicināts un izredzēts” Elīna Zālīte tõlkes ilmus 1940.

4. Adolf Hint (õieti: Adolf Edmund Hint) muutus raamatukaantel Aadu Hindiks 1940. aastatel.

5. „Mikumärdi” (Mikumerdi, 1930) ja „Põrunud aru õnnistus” (Neprāta svētlaime, 1932) R. Valdessi (õieti Rihards Ferdinands Bērziņ̌̌, 1888-1942) tõlkes. Bērziņš on läti keelde tõlkinud näiteks ka Tuglase novellid „Suveöö armastus” ning „Popi ja Huhuu” (1922); just Tuglase tegelaselt Arthur Valdeselt pärineb tema pseudonüüm. 